\title{
Fast re-oxidation kinetics and conduction pathway in Spark Plasma Sintered
} ferroelectric ceramics

M. Legallais, S. Fourcade, U-C. Chung, D. Michau, M. Maglione, F. Mauvy and C. Elissalde

CNRS, Université de Bordeaux, ICMCB

87 avenue du Dr. A. Schweitzer, F-33608 Pessac, France

\begin{abstract}
The re-oxidation kinetics of $\mathrm{BaTiO}_{3}$ ceramics sintered by Spark Plasma Sintering (SPS) was investigated using in-situ impedance spectroscopy. Thanks to the flexibility of the SPS process, the grain size of the dense ceramics was tuned from $0.5 \mu \mathrm{m}$ to $10 \mu \mathrm{m}$. The reoxidation kinetics are found to be very fast regardless of the grain size and a full re-oxidation of the ceramics are achieved after 20 hours of exposure to an ambient environment at only $600^{\circ} \mathrm{C}$. The residual density of charge carriers is reduced when using finer starting powders. SPS ceramics made with micrometer size grains demonstrate a residual charge-carrier density that is one tenth that of ceramics made from $10 \mu \mathrm{m}$ particles. Grain-boundary conduction is dominant through fine-grain SPS ceramics. This latter feature is similar to $\mathrm{BaTiO}_{3}$ sintered using the conventional route with $10 \mu \mathrm{m}$ size grain. Finally, the critical grain size for optimal dielectric permittivity is found to shift from $0.7 \mu \mathrm{m}$ in standard ceramics to $1.5 \mu \mathrm{m}$ in SPS ceramics.
\end{abstract}

Keywords: $\mathrm{BaTiO}_{3}$, SPS, dielectric properties, Impedance Spectroscopy, oxidation process

\section{Introduction}

The quest for improved functionalities in ferroelectric ceramics requires a control of composition, microstructure and defect chemistry. Ferroelectric materials which display the highest dielectric permittivities are very sensitive to defects because of the long scale correlation of their lattice features. As a result, a large density of chemical, structural or charged defects can strongly impact the bulk properties, artificially raising the permittivity and strongly increasing the dielectric losses $[1,2]$. The sintering step is critical with respect to 
point-defect concentration and mobility; - these point defects are mainly oxygen vacancies in ferroelectric perovskites. Consequently, the control of the dielectric characteristics, in particular when decreasing grain size, remains a major issue to address the challenging requirements of practical electronic devices.

In recent years, Spark Plasma Sintering (SPS) has emerged as an effective method for producing ferroelectric materials with controlled micro-nanostructures in the field of ferroelectric materials [3-6]. The simultaneous action of uniaxial pressure and pulsed electrical current produces efficient heat transfer and fast sintering kinetics [5]. As a result, grain size, strain and interface driven properties can be tailored to achieve desirable bulk properties [7, 8]. However minimizing extrinsic contributions to the dielectric properties remains challenging.

Table 1 provides a summary of experimental conditions used in previous work to synthesize high-density $\mathrm{BaTiO}_{3}$ using Spark Plasma Sintering [9-24]. When utilizing sub-micron starting powders $(20-700 \mathrm{~nm})$, SPS sintering temperatures and pressures in the range of $800-1200^{\circ} \mathrm{C}$ and $40-100 \mathrm{Mpa}$ are needed to keep the final grain size below one micron. SPS is usually performed under low oxygen partial pressure, a re-oxidation step is necessary to remove oxygen vacancies associated to the reduction of titanium $\left(\mathrm{Ti}^{4+}\right.$ into $\left.\mathrm{Ti}^{3+}\right)$ and to recover insulating properties. This post-sintering annealing, usually performed under air in the temperature range $700-1000{ }^{\circ} \mathrm{C}$ over $1-24$ hours, is dependent on both the initial particle size and the SPS sintering temperature (Table 1). Such a post-sintering treatment is a key step to control the number of charged defects in the final ceramic; its optimization can lead to improved dielectric performances.

The effect of the annealing process on oxygen vacancies and related electrical inhomogeneity in porous and dense barium strontium ceramics was recently discussed [25, 26]. The final properties are influenced by the localization of oxygen vacancies at the grain boundaries and/ or within the grains and their diffusion pathway during the annealing. As defect chemistry is highly dependent on the microstructure and the density of grain boundaries, there is great motivation to tailor the annealing process to achieve the desired electrical properties. While SPS is attributed to a decrease in grain-boundary resistivity, the fundamental effects of SPS on electrical properties remain not yet clarified [20, 22, 23, 27, 28].

In the present study, we investigate the influence of the sintering conditions on the electrical behavior and microstructural features of barium titanate fabricated by conventional sintering (CS) and SPS. We discriminate the grain and grain-boundary contributions by combining complex impedance spectroscopy with dielectric measurements. The impact of the sintering 
process and of the post sintering annealing on the resulting grain size, defect profiles, and electrical behavior is discussed.

\begin{tabular}{|c|c|c|c|c|}
\hline $\begin{array}{l}\text { Initial grain size } \\
\qquad(\mu \mathrm{m})\end{array}$ & $\begin{array}{c}\text { SPS experimental conditions } \\
\text { (temperature, pression, heating rate, } \\
\text { duration) }\end{array}$ & $\begin{array}{c}\text { Final } \\
\text { grain size } \\
(\mu \mathrm{m})\end{array}$ & $\begin{array}{c}\text { Relative } \\
\text { density } \\
(\%)\end{array}$ & $\begin{array}{l}\text { Post annealing } \\
\text { Under Air }\end{array}$ \\
\hline $\mathrm{NC}[9]$ & $1150^{\circ} \mathrm{C}, 50 \mathrm{MPa}, 25^{\circ} \mathrm{C} \cdot \mathrm{min}^{-1}, 3 \mathrm{~min}$ & 0.056 & 98 & $850^{\circ} \mathrm{C} 15 \mathrm{~min}$ \\
\hline $\mathrm{NC}[10]$ & $1150^{\circ} \mathrm{C}, 50 \mathrm{MPa}, 25^{\circ} \mathrm{C} \cdot \mathrm{min}^{-1}, 3 \mathrm{~min}$ & $\begin{array}{l}0.056- \\
0.072\end{array}$ & 92 & $850^{\circ} \mathrm{C} 5 \mathrm{~min}$ \\
\hline $0.016[11]$ & $\begin{array}{c}1000-1250^{\circ} \mathrm{C}, 50-100 \mathrm{MPa}, 200^{\circ} \mathrm{C} \cdot \mathrm{min}^{-1}, \\
2-6 \mathrm{~min}\end{array}$ & $\begin{array}{l}0.092- \\
0.936\end{array}$ & $97-99$ & $800^{\circ} \mathrm{C} 24 \mathrm{~h}$ \\
\hline $0.050-0.070[12]$ & $900-1050^{\circ} \mathrm{C}, 50 \mathrm{MPa}, 50^{\circ} \mathrm{C} \cdot \mathrm{min}^{-1}, 3-5 \mathrm{~min}$ & $0.21-0.67$ & 93-98 & $1050^{\circ} \mathrm{C} 5 \mathrm{~min}$ \\
\hline $0.015-0.040[13]$ & $950-1050^{\circ} \mathrm{C}, 75 \mathrm{MPa}, 100^{\circ} \mathrm{C} \cdot \mathrm{min}^{-1}, 5 \mathrm{~min}$ & $\begin{array}{l}0.150- \\
0.750\end{array}$ & $82-99$ & $\begin{array}{l}\text { Specific annealing } \\
\text { at } 1300^{\circ} \mathrm{C} 30 \mathrm{~min}\end{array}$ \\
\hline $0.03[14]$ & $\begin{array}{c}1112^{\circ} \mathrm{C}, 50 \mathrm{MPa}, 24 \text { and } 150^{\circ} \mathrm{C} \cdot \mathrm{min}^{-1}, \\
3 \mathrm{~min}\end{array}$ & $0.2-0.4$ & 97 & $750^{\circ} \mathrm{C} 15 \mathrm{~min}$ \\
\hline $0.02-0.03[15]$ & $900-1350^{\circ} \mathrm{C}, 40 \mathrm{MPa}, \mathrm{NC}, 1-2 \mathrm{~min}$ & 0.050 & $65-92$ & $800^{\circ} \mathrm{C} 24 \mathrm{~h}$ \\
\hline $0.02-0.03[16]$ & $\begin{array}{c}800-850^{\circ} \mathrm{C}, 70 \mathrm{MPa}, 400^{\circ} \mathrm{C} \cdot \mathrm{min}^{-1}, 2-7 \\
\min \end{array}$ & $0.02-0.1$ & $95-99$ & $\mathrm{NC}$ \\
\hline $0.03[17]$ & $800^{\circ} \mathrm{C}, 100 \mathrm{MPa}, 200^{\circ} \mathrm{C} \cdot \mathrm{min}^{-1}, 2 \mathrm{~min}$ & 0.05 & 96 & $700^{\circ} \mathrm{C}$ \\
\hline $0.03-0.04[18]$ & $800^{\circ} \mathrm{C}, 100 \mathrm{MPa}, 200^{\circ} \mathrm{C} \cdot \mathrm{min}^{-1}, 2 \mathrm{~min}$ & 0.05 & 97 & $\mathrm{NC}$ \\
\hline $0.030-0.040[3]$ & $\begin{array}{c}800-1000^{\circ} \mathrm{C}, 100 \mathrm{MPa}, 200^{\circ} \mathrm{C} \cdot \mathrm{min}^{-1}, 2- \\
5 \mathrm{~min}\end{array}$ & $0.05-0.3$ & $94-97$ & $\begin{array}{c}700-800^{\circ} \mathrm{C} \\
1-10 \mathrm{~h}\end{array}$ \\
\hline [19] $0.2-0.7$ & $\begin{array}{l}800-1200^{\circ} \mathrm{C}, 20-40 \mathrm{MPa}, \\
50-400^{\circ} \mathrm{C} \cdot \mathrm{min}^{-1}, 0-5 \mathrm{~min}\end{array}$ & $0.1-2.5$ & $82-98$ & $900^{\circ} \mathrm{C} 2 \mathrm{~h}$. \\
\hline [20] $0.2-0.6$ & $1000^{\circ} \mathrm{C}, 39 \mathrm{MPa}, 200^{\circ} \mathrm{C} \cdot \mathrm{min}^{-1}, 3 \mathrm{~min}$ & $0.2-1$ & 95 & $900^{\circ} \mathrm{C} 2 \mathrm{~h}$. \\
\hline $0.1-0.5[21]$ & $900-1200^{\circ} \mathrm{C}, 39 \mathrm{MPa}, 200^{\circ} \mathrm{C} \cdot \mathrm{min}^{-1}, 5 \mathrm{~min}$ & $0.3-1$ & 95 & $1000^{\circ} \mathrm{C} 2 \mathrm{~h}$ \\
\hline $0.6[22]$ & $1100^{\circ} \mathrm{C}, 39 \mathrm{MPa}, 200^{\circ} \mathrm{C} \cdot \mathrm{min}^{-1}, 3 \min$ & 0.6 & 97 & $1000^{\circ} \mathrm{C} 2 \mathrm{~h}$ \\
\hline $\begin{array}{l}1- \\
0.1[23]\end{array}$ & $\begin{array}{l}1080-1240^{\circ} \mathrm{C}, 85 \mathrm{MPa}, 5 \mathrm{~min} . \\
1000-1160^{\circ} \mathrm{C}, 85 \mathrm{MPa}, 5 \mathrm{~min} .\end{array}$ & $\begin{array}{c}0.8-18.5 \\
0.6-9.6\end{array}$ & $\begin{array}{c}98-99 \\
98-99.5\end{array}$ & $900^{\circ} \mathrm{C} 2 \mathrm{~h}$. \\
\hline $0.05[24]$ & $1000-1080^{\circ} \mathrm{C}, 85 \mathrm{MPa}, 5 \mathrm{~min}$. & $0.7-8$ & $\mathrm{NC}$ & $900^{\circ} \mathrm{C} 2 \mathrm{~h}$. \\
\hline
\end{tabular}

Table 1 Grain size, sintering and post annealing conditions of SPS sintered $\mathrm{BaTiO}_{3}$ ceramics reported in literature (1999-2016). 


\section{Experimental}

\subsection{Preparation of samples}

To ensure reproducibility, two commercial high purity powders were used (>99.9\%) with different particle size (supplied by Sakai Chemical Industry Co., Japan). Room-temperature X-ray diffraction analysis revealed no secondary phase (such as carbonates) according to the device's detection limit. Powder particle sizes were evaluated by linear-intercept method on scanning electron micrographs and were estimated to be $600 \pm 140 \mathrm{~nm}$ and $290 \pm 60 \mathrm{~nm}$ for each sample based on 115 particles. These two powders will be referred as BT600 and BT300 respectively. Dilatometry analysis (not shown) was performed under air to optimize the sintering temperatures and densification. The onset of the densification process started at 920 ${ }^{\circ} \mathrm{C}$ and continued up to about $1300{ }^{\circ} \mathrm{C}$ (temperature limit of the device).

\subsection{Conventional Sintering and Spark Plasma Sintering}

For the conventional sintering, the selected sintering temperature was $1350{ }^{\circ} \mathrm{C}$ considering that the densification extends beyond $1300{ }^{\circ} \mathrm{C}$ as shown by dilatometry analysis. The powder was shaped by applying 1 ton. $\mathrm{cm}^{-2}$ on a $20 \mathrm{~mm}$ diameter disk. The raw pellets were then heated from room temperature up to $1350{ }^{\circ} \mathrm{C}$ with a heating rate of $3{ }^{\circ} \mathrm{C} \cdot \mathrm{min}^{-1}$ and then maintained at this temperature for 4 hours. The samples were then cooled down to room temperature using the same ramp. Relative densities were calculated as the ratio between the experimental density from the mass and dimensions of the samples and the theoretical density of $\rho_{\mathrm{th}}=6.012 \mathrm{~g} \cdot \mathrm{cm}^{-3}$.

In the present work, powders were sintered by Spark Plasma Sintering (SPS) using SYNTEX, Dr. Sinter $515 \mathrm{~S}$ apparatus. SPS was carried out under vacuum and different sintering temperatures $\left(1100{ }^{\circ} \mathrm{C}, 1150{ }^{\circ} \mathrm{C}\right.$ and $\left.1200{ }^{\circ} \mathrm{C}\right)$ were selected in order to obtain different "electrical microstructures" in terms of $\mathrm{Ti}^{4+}-\mathrm{Ti}^{3+}$ reduction level. Short dwell time (5min) and high heating rates $\left(>250^{\circ} \mathrm{C} / \mathrm{min}\right)$ were used to improve densification while limiting grain growth. The pressure was applied from ambient temperature, maintained during the heating and until the end of the sintering temperature dwell, and then released during the cooling step down to $\mathrm{T} \leq 600{ }^{\circ} \mathrm{C}$. The pressure applied was in the range 60-100 MPa according to the sintering temperature. Graphite tools (mold and punches) were used. The interior of the mold 
was covered with graphite foil to minimize contact resistance between the sample and the different parts of the device and to ensure a better thermal tightness. The SPS set-up was maintained under low vacuum $(10 \mathrm{~Pa})$ to prevent oxidation of the graphite.

\subsection{Electric and dielectric measurements}

After SPS, the re-oxidation process of the ceramics and their subsequent electrical behavior were investigated. The quality of the electrical contacts can significantly affect the measurements. The current collection layer will depend not only on the choice of metal but also on the deposition technique. The in-situ monitoring by impedance spectroscopy of the reoxidation process required extremely stable electrodes. In the present study, platinum electrodes sputtered by Physical Vapor Deposition (PVD) have been selected. PVD can be performed at room temperature and contrary to other metals, platinum deposition does not require post-thermal treatment (which could partly re-oxide the sample) and remains stable up to $800^{\circ} \mathrm{C}$, temperature that corresponds to the average post-sintering re-oxidation temperature (Table 1).

Electrical measurements were performed using a Frequency Response Analyzer AUTOLAB PGSTAT302. A two contacts sample holder was used with gold grids as current collectors. The ceramic set-up allows performing measurements from $25^{\circ} \mathrm{C}$ to $900{ }^{\circ} \mathrm{C}$ under controlled gas (air, nitrogen, argon). The frequency range extends from $10 \mathrm{mHz}$ to $1 \mathrm{MHz}$. Data are collected, initially, using the Frequency Response Analyzer® software. ZView® program was used to determine the electrical characteristics using equivalent circuits modeling.

The dielectric measurements before and after re-oxidation were performed using an HP 4194A impedance bridge. The set-up includes a quartz enclosure and coaxial cables in order to limit high frequency electronic noise. The sample was placed between two brass electrodes. The characterizations have been made under primary vacuum and in the temperature range from $195{ }^{\circ} \mathrm{C}$ up to $230{ }^{\circ} \mathrm{C}$. The capacitance and dielectric losses versus both temperature and frequency were evaluated from a $\mathrm{R} / / \mathrm{C}$ equivalent circuit, directly included in the bridge. The associated permittivity has been deduced from the geometric factor of the sample and the capacitance values.

\section{Results and Discussion}




\subsection{BT600 comparative investigation: SPS versus conventional sintering}

\subsubsection{Microstructural characterizations}

The microstructures of SPS and CS ceramics observed by scanning electron microscopy are reported on Figure 1. After conventional sintering performed at $1350^{\circ} \mathrm{C}$, the pellets are of white color, meaning that a very low concentration of electronic defects should be present. The average grain diameter was determined on fracture surfaces using image processing (Image $\mathrm{J}$ ) and was estimated close to $10.7 \pm 3.7 \mu \mathrm{m}$ (Fig. 1a). The intergranular fracture mode and the low presence of micro-porosity are in good agreement with the high relative density measured $(>95 \%)$.

For ceramics sintered by SPS, an increase of grain size from about $1.5 \mu \mathrm{m}$ to $3.4 \mu \mathrm{m}$ is observed when increasing the sintering temperatures from 1100 to 1200 (Fig.1b-d). Only closed porosity remains and the relative density is higher than $97 \%$ for all the ceramics. The samples sintered by SPS have a blue/dark color stemming for titanium reduction and therefore, a larger $\mathrm{Ti}^{3+}$ to $\mathrm{Ti}^{4+}$ ratio can be expected for the highest sintering temperatures $\left(1150-1200^{\circ} \mathrm{C}\right)$ considering the change of color (inset fig. 1a-d)). It is worth noting that a pressure increase inside the sample chamber was observed during the heating treatment. Such an increase could be due to oxygen losses (reaction: $\mathrm{O}_{\mathrm{O}}{ }^{\mathrm{X}} \leftrightarrow 1 / 2 \mathrm{O}_{2}+\mathrm{V}_{\mathrm{O}}{ }^{\bullet \bullet}+2 \mathrm{e}^{\prime}$ ) associated to the reduction of titanium (following to the reaction: $\mathrm{Ti}^{4+}+\mathrm{e}^{\prime} \leftrightarrow \mathrm{Ti}^{3+}$ ). This degassing process could also be assigned to the graphite oxidation as $\mathrm{CO}$ or $\mathrm{CO}_{2}$, despite the low oxygen partial pressure in the SPS set-up.
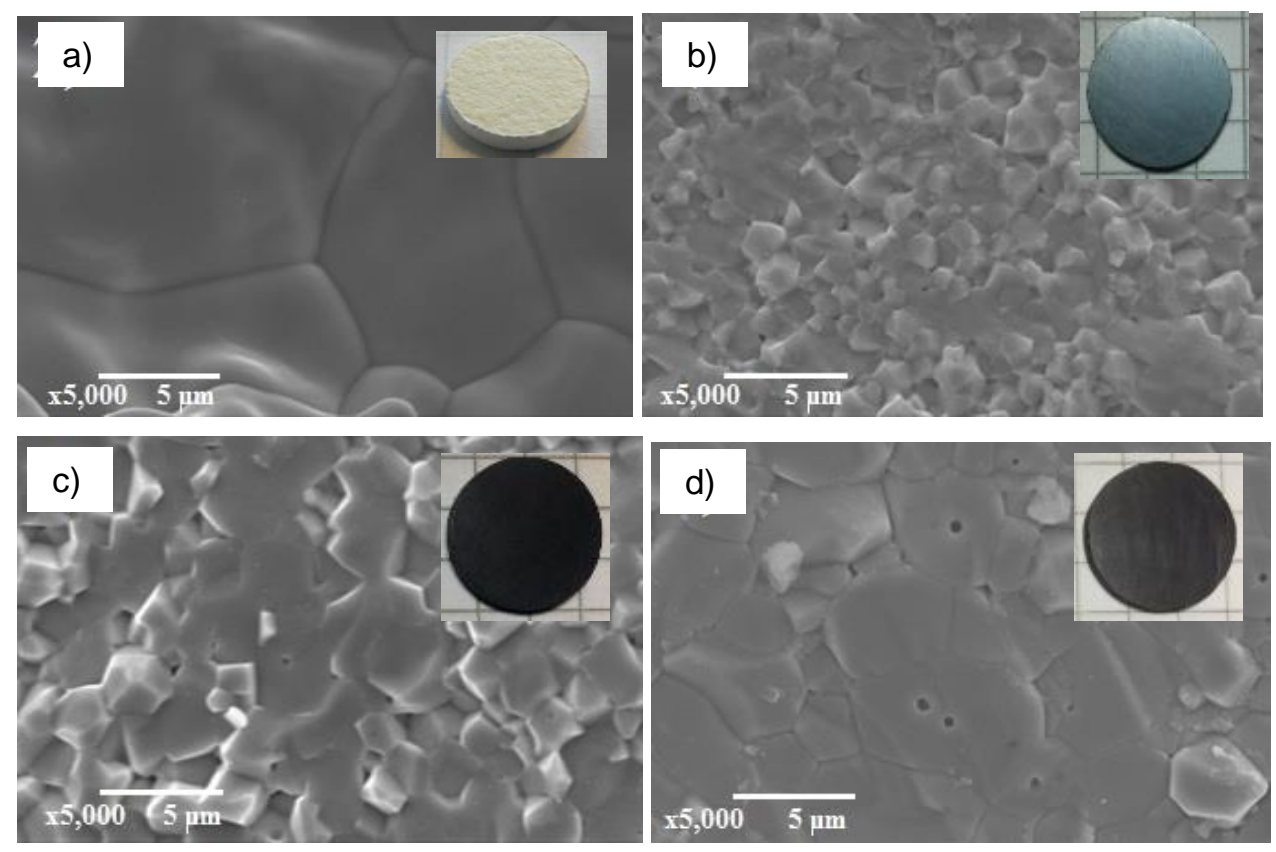
Fig. 1 SEM images of BT600 ceramics a) sintered at $1350^{\circ} \mathrm{C}$ by conventional sintering and bd) sintered by SPS at 1100,1150 and $1200^{\circ} \mathrm{C}$ respectively.

\subsubsection{Study of re-oxidation process after SPS}

The dielectric behavior of the ceramics was first checked directly after SPS sintering, before re-oxidation process. As expected, permittivity values measured at room temperature were higher than 20,000 and the dielectric losses reached huge values. These characteristics have been assigned to a large number of defects arising from the titanium reduction during SPS performed under low oxygen partial pressure.

\subsubsection{Oxidation kinetics: in situ experiments}

Preliminary tests showed that, regardless of SPS sintering temperature, the ceramics were fully re-oxidized in few hours from $700{ }^{\circ} \mathrm{C}$. As a consequence, the rapid kinetics of reoxidation of the system at this temperature does not allow accurate tracking by impedance spectroscopy. Therefore the working temperature was set at $600{ }^{\circ} \mathrm{C}$ to overcome this problem. Furthermore, the samples were brought under nitrogen when increasing the temperature up to the re-oxidation temperature in order to maintain the oxygen vacancy concentration before starting the kinetic study. When the working temperature was reached, an air stream was injected into the set-up marking the on-set of the re-oxidation process.

A summary of the conductivity evolution during the post sintering thermal treatment is depicted in Fig. 2. Three parts can be distinguished: the first heating under nitrogen shows a metallic type behavior because of the electronic defects. In the second step, the re-oxidation occurs under air at $600^{\circ} \mathrm{C}$ (versus time) and finally the conductivity of the re-oxidized compound is measured $\left(\mathrm{E}_{\mathrm{A}}=1.35 \mathrm{eV}\right)$. 




Fig. 2 : Conductivity during thermal treatments performed under nitrogen and air for BT600 powder sintered by Spark Plasma Sintering at $1200^{\circ} \mathrm{C}$.

As an illustration, the impedance measurements performed in-situ during the re-oxidation process under air at $600^{\circ} \mathrm{C}$ is shown on Fig. 3a for the SPS ceramic sintered at $1200^{\circ} \mathrm{C}$. One depressed semi-circle was obtained in the investigated frequency range. One R // C circuit was therefore used for modeling and allowed to deduce the equivalent conductivity $\left(\sigma_{\mathrm{eq}}\right)$ and equivalent capacitance $\left(\mathrm{C}_{\mathrm{eq}}\right)$. The associated time dependence of both the equivalent conductivity and the capacitance of the sample are reported on Fig. $3 \mathrm{~b}$. 
a)

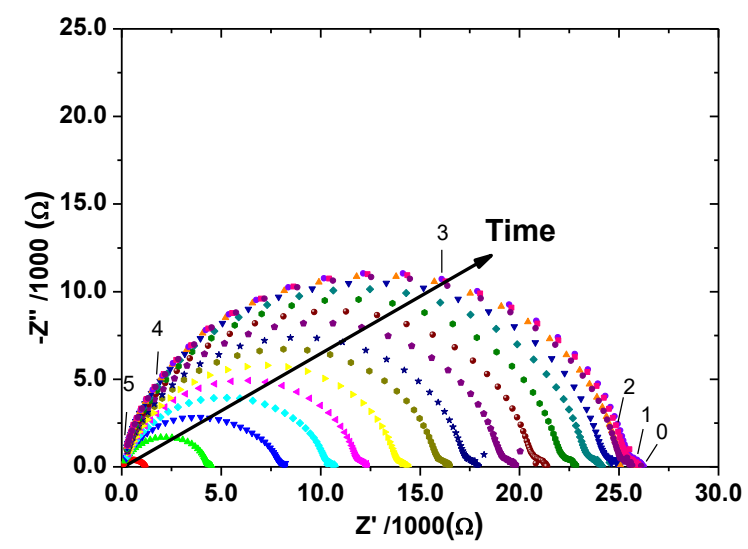

b)



Fig. 3 : SPS ceramic sintered at $1200^{\circ} \mathrm{C}$ : a) Typical Nyquist diagrams measured during the reoxidation process at $600^{\circ} \mathrm{C}$ under air (the numbers by data points are frequency logarithms); b) associated time dependence of the equivalent conductivity $\left(\sigma_{\text {eq }}\right)$ and capacitance $\left(\mathrm{C}_{\mathrm{eq}}\right)$.

As expected, the conductivity decreases versus time during the re-oxidation according to the reaction: $2 \mathrm{Ti}^{3+}+\mathrm{V}_{\mathrm{O}} \bullet+\frac{1}{2} \mathrm{O}_{2} \leftrightarrow \mathrm{O}_{\mathrm{O}}{ }^{\mathrm{X}}+2 \mathrm{Ti}^{4+}$. Because of its proximity from the conduction band, the $\mathrm{Ti}^{3+}$ level increases the conductivity which is then reduced when the reaction corresponding to the above equation takes place. At the same time, the capacitance decreases thanks to a reduction in the density of charged defects. The plateau in conductivity reached after about 20 hours steams for a full oxidation $\left(\mathrm{BaTiO}_{3-\delta}+\delta / 2 \mathrm{O}_{2} \leftrightarrow \mathrm{BaTiO}_{3}\right)$ (Fig. 3b). This hypothesis is in agreement with the relatively similar final capacitance values for all the SPS samples independently of the grain size.

Once the steady state reached, a temperature cooling was performed (Fig. 2). Impedance diagrams have been recorded during the temperature decrease. In order to compare the electrical parameters, the impedance diagrams have been measured with conventionally sintered sample. Typical Nyquist plot corresponding to CS ceramics displays two depressed 
semi-circles (Fig.4). An equivalent circuit based on two R//C associated in series have been used for data simulation. According to the fitting, the frequency relaxations and the associated capacitive effects have been deduced. The impedances observed can be assigned to the bulk contribution in the high frequency range $\left(\mathrm{C}_{\mathrm{Bulk}} \sim 10^{-10} \mathrm{~F} . \mathrm{cm}^{-1}\right)$ and to the grain boundaries contribution in the low frequency range $\left(\mathrm{C}_{\mathrm{GB}} \sim 10^{-8} \mathrm{~F} . \mathrm{cm}^{-1}\right)$.

Considering as reference the CS electrical parameters, the impedance measured for SPS ceramic can be assigned to an inter-granular contribution. Effectively, both the equivalent capacitance $\left(\mathrm{C}_{\mathrm{eq}} \sim 10^{-8} \mathrm{~F} . \mathrm{cm}^{-1}\right)$ and the calculated activation energies are similar when comparing the bulk contribution relative to SPS and CS ceramics. Such an attribution is also supported by the evolution of the relaxation frequencies (not shown) which followed the same trend. These characteristics stem for a conduction mechanism governed by the grain boundaries in $1200^{\circ} \mathrm{C}$ SPS ceramics.

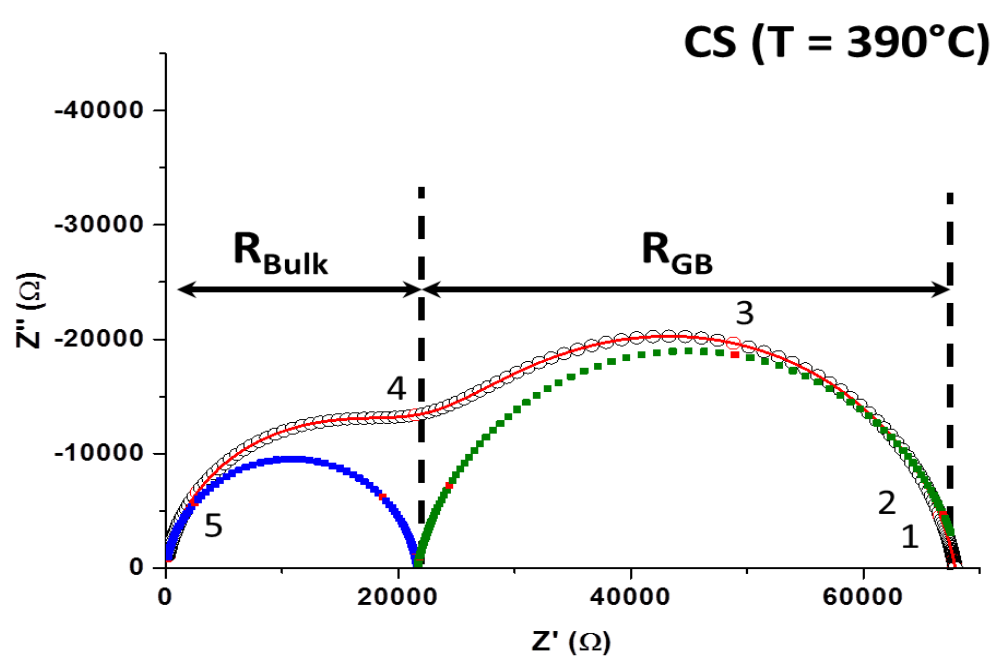

Fig. 4 : Typical impedance diagram measured at $\mathrm{T}=390^{\circ} \mathrm{C}$ for $\mathrm{CS}$ sample. Bulk (R $\mathrm{R}_{\text {Bulk}}$ ) and grains boundaries $\left(\mathrm{R}_{\mathrm{GB}}\right)$ resistances are given in ohm. The numbers by data points are the frequency logarithms

\subsubsection{Electrical properties after re-oxidation}

After the re-oxidation process at $600^{\circ} \mathrm{C}$, and whatever the sintering temperature of the SPS ceramics, a white color similar to that obtained after conventional sintering is recovered. First of all, the real permittivity and dielectric losses were measured as a function of temperature to 
confirm the full re-oxidation of the SPS ceramics. To do so, the dielectric parameters are compared to the-ones obtained for conventional sintering. The results below are plotted for a frequency of $10 \mathrm{kHz}$ (Fig. 5), but the frequency dispersion remains very low in the range $100 \mathrm{~Hz}-1 \mathrm{MHz}$.

a)

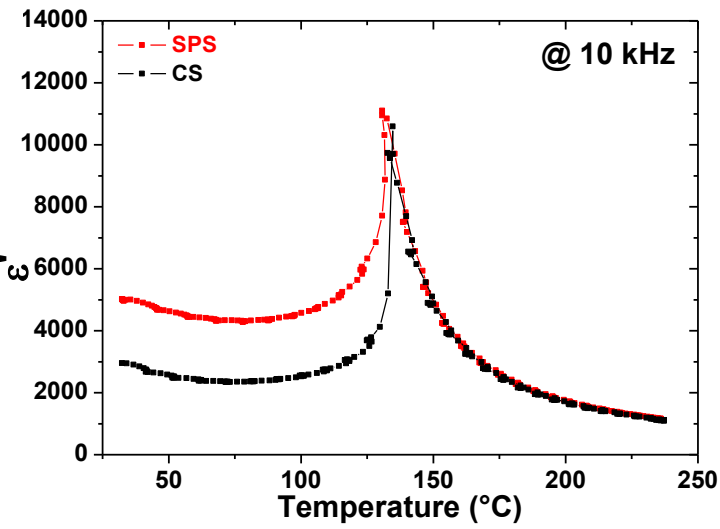

b)

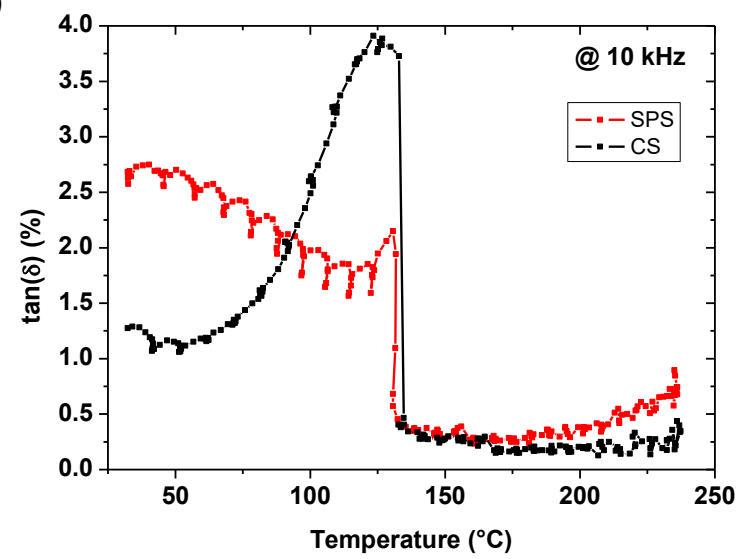

Fig. 5: Evolution of the real part of permittivity a) and the dielectric losses b) at $10 \mathrm{kHz}$ as a function of the temperature for ceramics obtained by SPS at $1200^{\circ} \mathrm{C}$ after re-oxidation and conventional sintering. (Note that the observed ripples are assigned to temperature oscillations).

As observed in Fig. 5, whatever the sintering process, the Curie temperature is close to $130{ }^{\circ} \mathrm{C}$ with a maximum of permittivity reaching 11,000 and low dielectric losses $(\tan (\delta)<4 \%)$. Typical dielectric behavior of $\mathrm{BaTiO}_{3}$ ceramics has been restored after re-oxidation of SPS ceramics at only $600{ }^{\circ} \mathrm{C}$. It is worth noting that this temperature is well below the postsintering treatments currently used in the literature $\left(850{ }^{\circ} \mathrm{C}-1200{ }^{\circ} \mathrm{C}\right)$. Remarkably, CS and SPS samples show similar permittivities in the paraelectric phase while higher values are reached in the ferroelectric phase for the SPS ceramic. 
Impedance measurements performed on the CS and the re-oxidized SPS ceramics were then analyzed and compared in the temperature range $350^{\circ} \mathrm{C}-600^{\circ} \mathrm{C}$. The conductivity versus the reverse of the temperature is reported on Fig.6. The bulk and grain boundaries contributions have also been reported as well as the total ceramic conductivity according to the relation (1) :

$$
\sigma_{\text {tot }}=1 /\left(\mathrm{R}_{\mathrm{Bulk}}+\mathrm{R}_{\mathrm{GB}}\right) \times \mathrm{L} / \mathrm{S}
$$

where $R_{B u l k}$ is the intra-granular resistance and $R_{G B}$ is the inter-granular resistance (see Fig. 4), $\mathrm{L}$ is the thickness and $\mathrm{S}$ the surface area of the sample.

It can be noticed that the bulk conductivity is higher than the grain boundaries one (Fig.6). In addition, the activation energy is lower for the bulk $\left(\mathrm{E}_{\mathrm{A}, \text { bulk }}=0.99 \mathrm{eV}\right)$ compared to the grain boundaries $\left(\mathrm{E}_{\mathrm{A}, \mathrm{GB}}=1.32 \mathrm{eV}\right)$. Concerning the total conductivity, the Arrhenius plots show that the activation energy of CS and SPS ceramics are closed: $\mathrm{E}_{\mathrm{A}, \mathrm{CS}}=1.21 \mathrm{eV}$ and $\mathrm{E}_{\mathrm{A}, \mathrm{SPS}}=1.35 \mathrm{eV}$ respectively. This means that the transport mechanism is certainly similar, keeping the oxygen vacancies as a source for the conductivity process. The Arrhenius pre-factor for total conductivity, is however significantly lower in SPS ceramics $\left(\sigma^{\circ}=1255 \Omega^{-1} \cdot \mathrm{cm}^{-1}\right.$ and $\sigma^{\circ}=$ $7480 \Omega^{-1} . \mathrm{cm}^{-1}$ for SPS and CS respectively) pointing to a lower density of charge carriers according to the relation (2) :

$$
\sigma=\mathrm{q}_{\mathrm{e}} \times \mu \times \mathrm{n}_{\mathrm{c}}
$$

where $\mathrm{q}_{\mathrm{e}}$ is the electronic charge $\left(1.6 \times 10^{-19} \mathrm{C}\right), \mu$ is the mobility of the charge carriers, $\mathrm{n}_{\mathrm{c}}$ is the concentration of charge carriers.

The electrical measurements after re-oxidation show that the low density of point defects in SPS ceramics after re-oxidation leads to lower grain boundary conductivity. In a first attempt, the low density of point defects pointed out in the re-oxidized SPS ceramic confirms the efficiency of the thermal treatment at a temperature as low as $600^{\circ} \mathrm{C}$. Such fast oxidation kinetics can arise from a weak stability of the defects after SPS due to the short duration and low temperature of this process. However, at this stage, the discussion cannot be extended to a comparison between the Arrhenius pre-factors of CS and SPS ceramics in terms of defects density because of the significant difference in grain size between the two ceramics (SPS1200 : $3.4 \mu \mathrm{m}-\mathrm{CS}: 10 \mu \mathrm{m})$. 


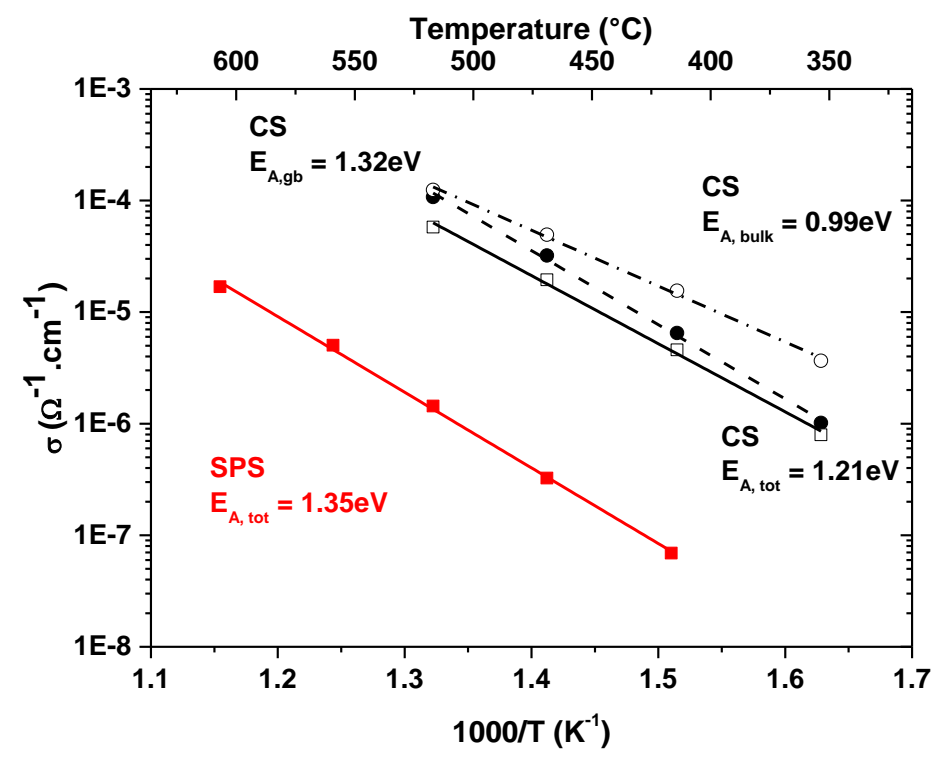

Fig. 6: Arrhenius plots of the total conductivity for CS ( $\square$ ) and SPS ceramics (a). The corresponding sintering temperatures and grain size $\phi_{\text {grain }}$ for CS and SPS are $1350^{\circ} \mathrm{C}-10 \mu \mathrm{m}$ and $1200^{\circ} \mathrm{C}-3.4 \mu \mathrm{m}$, respectively. The bulk (०) and grain boundaries $(\bullet)$ conductivities of the CS sample are also reported.

A twofold strategy is proposed to discriminate between the grain size and the type of sintering process in the contribution of density of point defects to the conductivity. The objective is also to define the preferential conduction pathway. First, powders with different initial particles size were sintered by SPS to extend the range of electrically probed microstructures. Then, the electrical properties of SPS and CS ceramics with similar grain size (close to 10 $\mu \mathrm{m})$ were compared.

\subsection{Correlations between dielectric properties and ceramic microstructures}

\subsubsection{Spark Plasma Sintering of BT300}

Starting from BT300 powder, different sintering temperatures have been selected in the range $1000^{\circ} \mathrm{C}-1200^{\circ} \mathrm{C}$. A drastic evolution of the microstructure is observed according to the sintering temperature (Fig.7). 

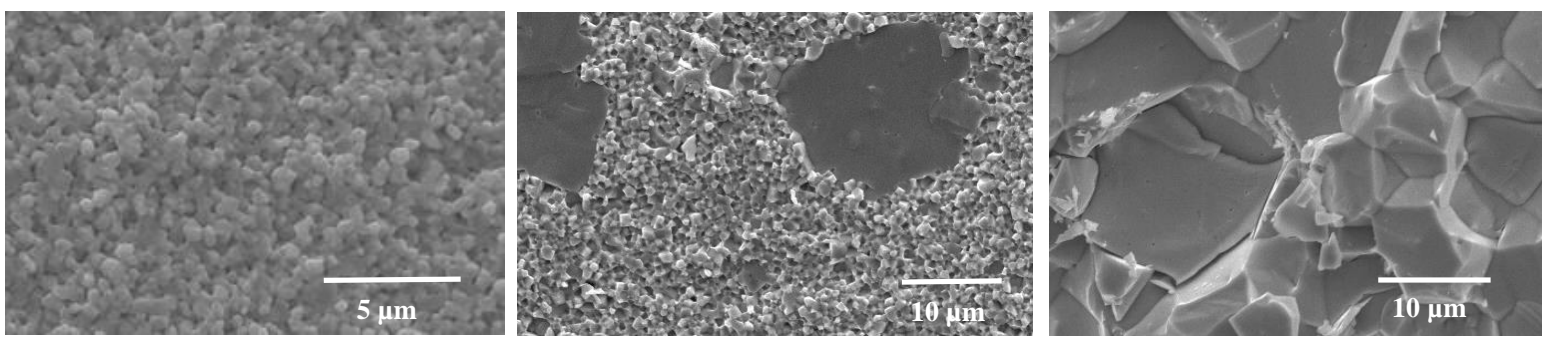

Fig. 7: SEM images of BT300 sintered by SPS at a) $1000^{\circ} \mathrm{C}$, b) $1100^{\circ} \mathrm{C}$, and c) $1200^{\circ} \mathrm{C}$.

The ceramic sintered at the lowest temperature $\left(1000^{\circ} \mathrm{C}\right)$ exhibits a homogeneous and finegrained microstructure $\left(0.55 \mu \mathrm{m} \leq \phi_{\text {grain }} \leq 0.85 \mu \mathrm{m}\right)$ (Fig. 7a). Increasing the sintering temperature up to $1100^{\circ} \mathrm{C}$ led to a bimodal microstructure with very large grains $\left(\phi_{\text {grain }}>\right.$ $10 \mu \mathrm{m})$ dispersed within a well densified matrix made of a monodisperse distribution of submicrometer grains (Fig. 7b). Finally, grain growth occurs when the sample is sintered at the highest temperature $1200^{\circ} \mathrm{C}$ (Fig.7c). The ceramic is fully dense and very large grains are observed $\left(\phi_{\text {grain }}=11.9 \mu \mathrm{m}\right)$. It is worth noting that the initial particle size influences strongly the final microstructure when the sintering temperature reaches $1200^{\circ} \mathrm{C}$. Indeed a significant increase from $\phi_{\text {grain }} \leq 3.4 \mu \mathrm{m}$ to grain size larger than $10 \mu \mathrm{m}$ is observed when decreasing the initial grain size (from BT600 to BT300). Moreover, all the ceramics have a relative density higher than $92 \%$ regardless of the sintering temperature. The corresponding relative density values are reported on Fig.8.

A significant evolution of the microstructure as a function of the sintering temperature was highlighted through the microstructural investigation. Reporting grain size as a function of sintering temperature allows to define a kinetic window (hatched area) for which the densification process may be separated from the grain growth process (Fig. 8). This observation is in agreement with the results obtained by J. Liu et al. [30]. Such behavior can be explained by the higher reactivity of the fine initial powders i.e. BT300 and can be ascribed to the formation of aggregates within the green compact that may induce exaggerated grain growth. However, such differences do not impact the final relative density. 


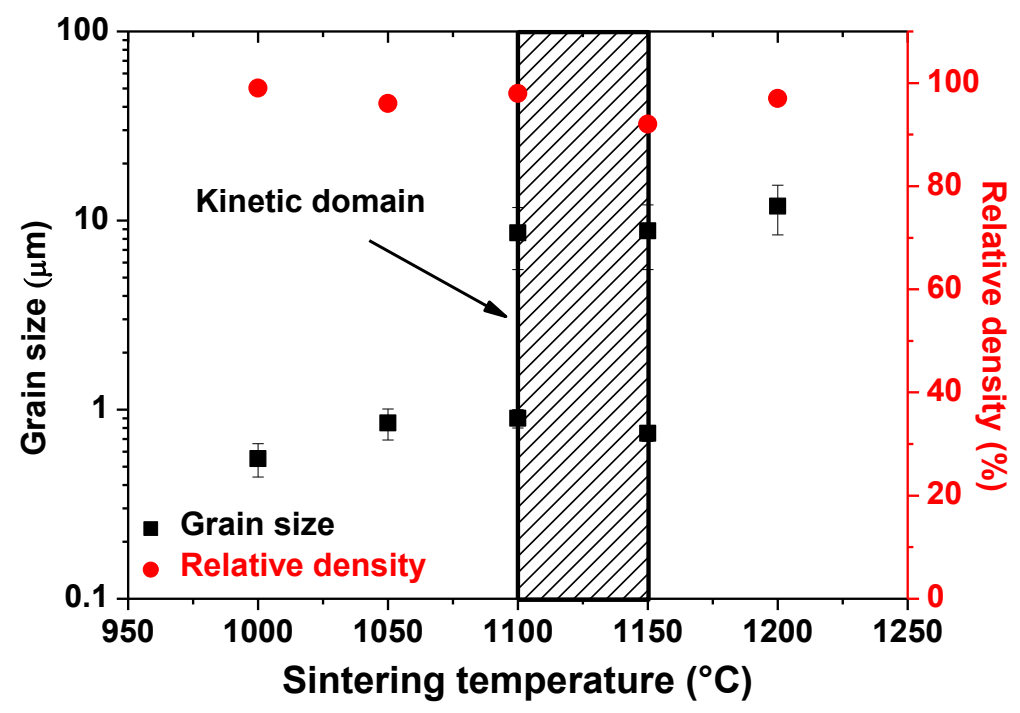

Fig. 8 : Evolution of the grain size $\phi_{\text {grain }}$ and the $\mathrm{BaTiO}_{3}$ ceramic relative density versus the SPS sintering temperature.

\subsubsection{Influence of the ceramic microstructure on the dielectric properties}

By using powders of different initial particle size and varying the sintering temperature, a set of dense SPS ceramics with grain size ranging from 0.55 to about $12 \mu \mathrm{m}$ were obtained. All the SPS ceramics have been re-oxidized at $600^{\circ} \mathrm{C}$ according to the protocol described in section 3.1.2.1. The efficiency of the annealing process at $600^{\circ} \mathrm{C}$ towards a full re-oxidation was proved whatever the grain size, steaming for fast re-oxidation kinetics in SPS ceramics. After re-oxidation, dielectric measurements performed on each ceramic have allowed to evaluate the evolution of the room temperature permittivity as a function of the grain size (Fig. 9). 


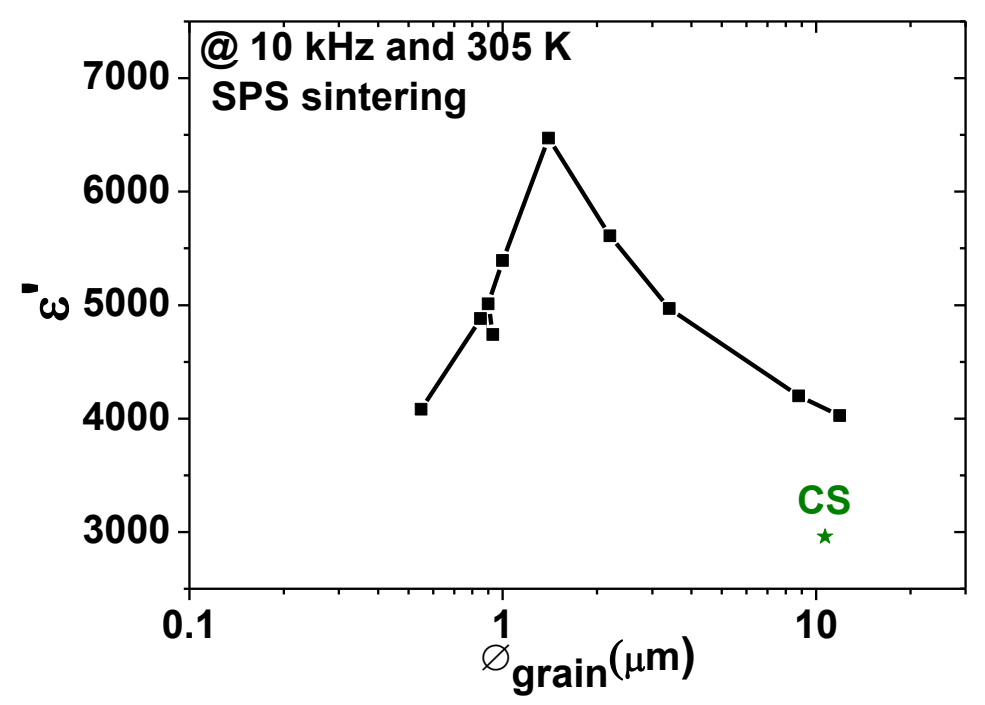

Fig. 9: Dielectric permittivity of SPS ceramics recorded at room temperature and at $10 \mathrm{kHz}$ as a function of the final grain size $\phi_{\text {grain }}$.

A behavior similar to that usually described in literature is observed [13, 23, 31]. Even with some spreading resulting from the diverse processing of ceramics, all these studies converge towards a maximum of permittivity for an average grain size in the range $\phi_{\text {grain }}=0.8-1 \mu \mathrm{m}$. In the present report, this maximum occurs at a larger grain size i.e. $\phi_{\text {grain }}=1.5 \mu \mathrm{m}$. Tian et al. reported a similar increase in the specific case of initial BT micrometer size particles sintered by SPS [23]. Moreover, their study reports also room temperature permittivity higher in SPS ceramics than in ceramics performed by conventional sintering. The grain size dependence of the permittivity at room temperature is usually ascribed to different contributions including domain wall dynamics, internal stress and defects [23]. The lower permittivity value observed in CS ceramics was ascribed to domain wall pining by point defects [23]. As evidenced in our conductivity measurements, the density of charged point defects was shown to be low in the SPS ceramic sintered at $1200^{\circ} \mathrm{C}\left(\mathrm{BT} 600\right.$ - final grain size $\left.\phi_{\text {grain }}=3.4 \mu \mathrm{m}\right)$ thus assuming a weaker probability of domain wall pinning which can result in increased permittivity.

In order to identify the conduction mechanisms according to both the grain size and the sintering process, the Arrhenius plot of the conductivity and the associated capacitive effect have been measured on SPS ceramics with $11.9 \mu \mathrm{m}$ grain size (BT300) and compared to the SPS ceramic with lower grain size $\left(\phi_{\text {grain }}=3.4 \mu \mathrm{m}\right)$ and to the CS ceramic of similar grain size $\left(\phi_{\text {grain }}=10 \mu \mathrm{m}\right)($ Figs. 10a,b). 
a)

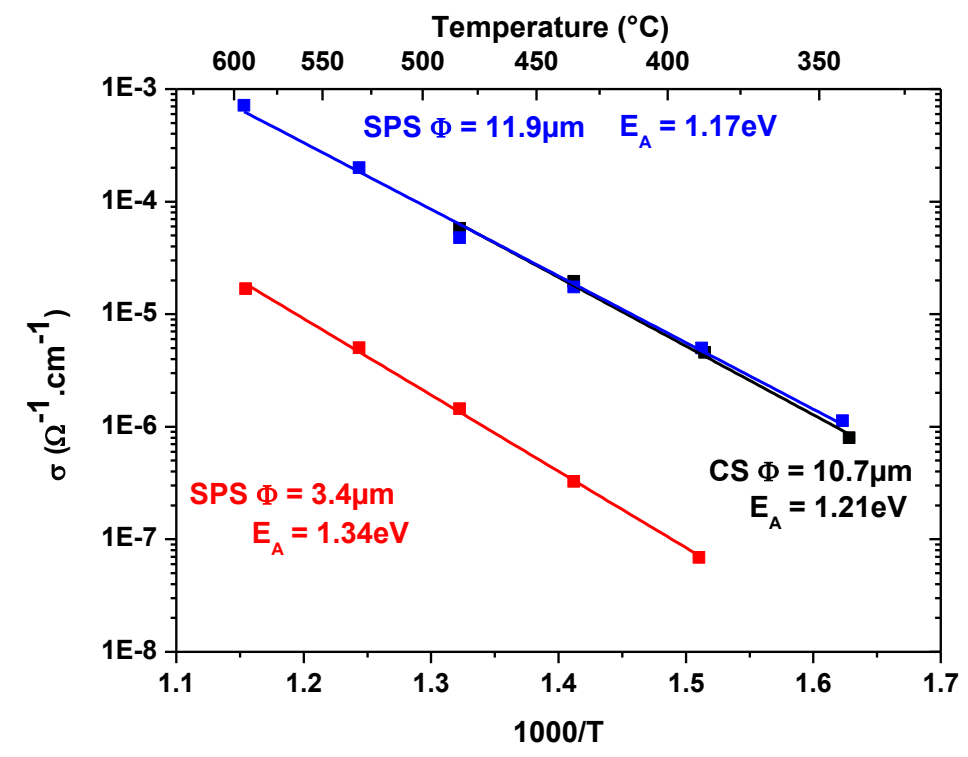

b)

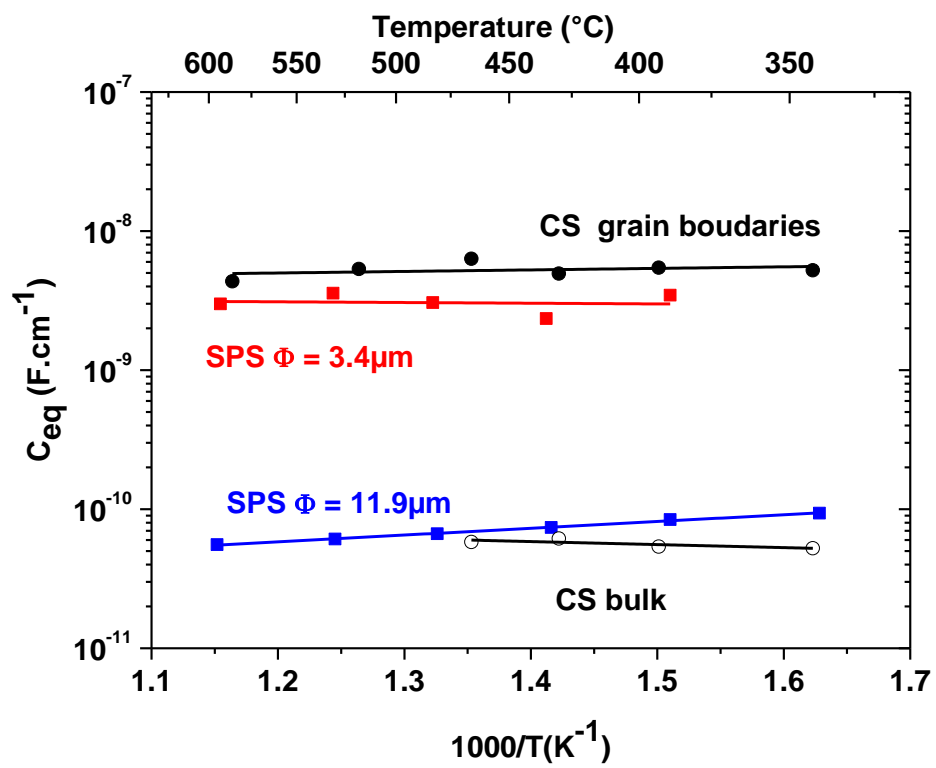

Fig.10 : Arrhenius plot of (a) the total conductivities for ceramics elaborated by SPS at $1200^{\circ} \mathrm{C}$ (BT600 - final $\phi_{\text {grain }} \approx 3.4 \mu \mathrm{m}(\mathbf{m})$ and BT300 - final $\phi_{\text {grain }} \approx 11.9 \mu \mathrm{m}(\mathbf{m})$ ) or conventional sintering process $\left(\phi_{\text {grain }} \approx 10.7 \mu \mathrm{m}\right)(\mathbf{\square})$ and (b) the capacitance characterizing the high frequencies and medium frequencies semicircles.

The activation energies are very similar for the three samples (in the range $1.17 \mathrm{eV}-1.34 \mathrm{eV}$ ) (Fig.10a). In addition, the Arrhenius pre-exponential factor $\sigma^{\circ}$ associated with SPS $11.9 \mu \mathrm{m}$ 
grain size reaches $8857 \Omega^{-1} \cdot \mathrm{cm}^{-1}$, a value close to the one obtained for the CS ceramics $\left(\sigma^{\circ}=\right.$ $\left.7480 \Omega^{-1} \cdot \mathrm{cm}^{-1}\right)$. It can be deduced that the charge carriers are the same for the SPS and CS samples and that the conduction mechanism could be similar involving oxygen vacancies.

Regarding to the total conductivity values and in the case of SPS ceramics with a larger grain size (see sample SPS $11.7 \mu \mathrm{m}$ ), the transport properties could be governed by the bulk contribution. When decreasing the grain size (see sample SPS $3.4 \mu \mathrm{m}$ ), the conductivity of the ceramic also decreases and the transport process seems to be controlled by the grain boundaries contribution.

According to Fig. 10b reporting the equivalent capacitances, the imaginary part of the impedance can be assigned to a specific contribution. Indeed, considering the results obtained on the CS sample, the capacitances around $10^{-10} \mathrm{~F}_{\mathrm{cm}} \mathrm{cm}^{-1}$ and $10^{-8} \mathrm{~F} . \mathrm{cm}^{-1}$ can be associated to the bulk and grain boundaries, respectively. It can be then deduced that the impedance measured with the smaller-grain SPS $\phi=3.4 \mu \mathrm{m}$ is mainly controlled by the grain boundaries contribution, whereas the impedance recorded with the larger-grained SPS $\phi=11.9 \mu \mathrm{m}$ is governed by the bulk contribution.

The frequency dependence of the permittivity can also be an effective tool to probe the defect density [32]. For this purpose, the room-temperature permittivity was calculated from the measured complex impedances for the different samples.

The step-like dispersion occurring at $390^{\circ} \mathrm{C}$ in the vicinity of $1 \mathrm{kHz}$ for both SPS and CS ceramics with grain size higher than $10 \mu \mathrm{m}$ stems from a dipolar relaxation (Fig. 11). As expected two different plateaus are observed for the CS ceramic. In the high frequency (HF) range, the permittivity is assigned to the bulk and in the low frequency (LF) range, the permittivity is attributed to the grain boundaries. Note that no plateau can be reached for SPS $\phi=11.9 \mu \mathrm{m}$, most probably because the relaxation towards the grain boundary plateau is to occur at frequencies lower than our frequency range $10 \mathrm{~Hz}$; this explains why no equivalent capacitance for grain boundaries could be reported for this sample (Fig.10). On the other hand, in the case of SPS $\phi=3.4 \mu \mathrm{m}$ sample, even if the HF bulk intrinsic permittivity is observed (Fig. 11), the associated capacitance cannot be deduced from the Nyquist diagrams because of the high value of the resistance of the sample. In this case, the grain boundaries impedance is so high that the bulk cannot be well fitted. 


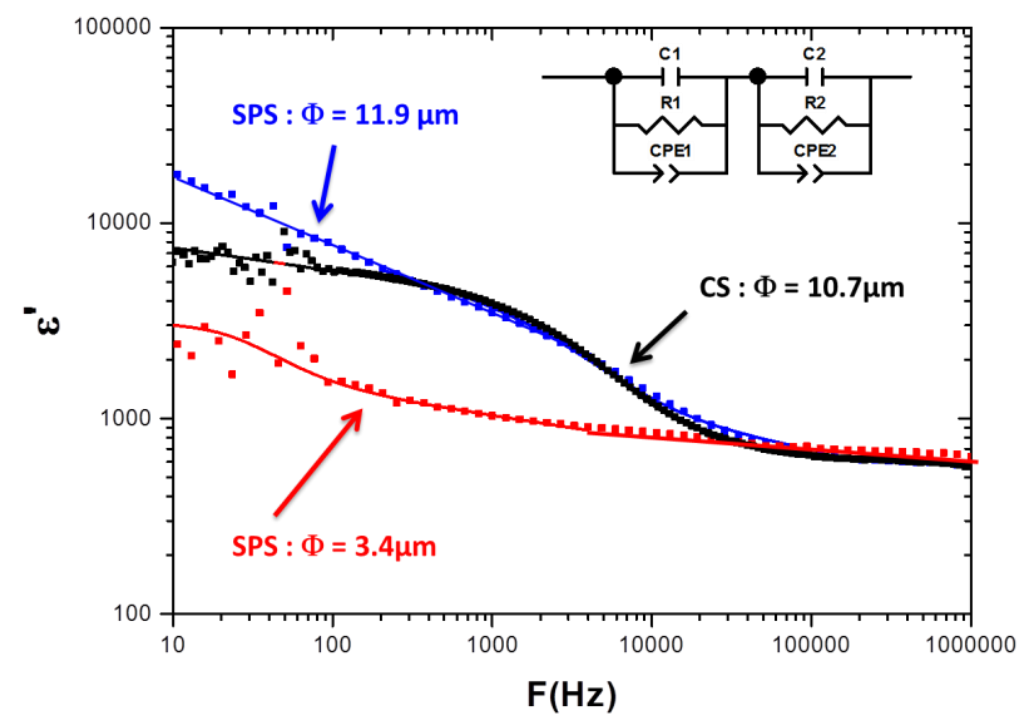

Fig.11: Evolution of the permittivity versus the frequency for SPS ceramics (BT600 - final $\phi_{\text {grain }}=3.4 \mu \mathrm{m}(\boldsymbol{\square})$ and BT300 - final $\left.\phi_{\text {grain }}=11.9 \mu \mathrm{m}(\boldsymbol{\bullet})\right)$ at $390^{\circ} \mathrm{C}$ and $\mathrm{CS}$ ceramics $\left(\phi_{\text {grain }}=\right.$ $10.7 \mu \mathrm{m})(\boldsymbol{\square})$. Insert: the equivalent circuit used for the data fitting.

These relaxations are in quantitative agreement with similar results in $\mathrm{BaTiO}_{3}$ single crystals and other perovskites ceramics [32]. Following this previous report, the dielectric relaxation can be linked to a space charge whose amplitude was shown to increase with the density of oxygen vacancies. Such a link was ascribed to free electronic carriers resulting from the oxygen non-stoichiometry.

In contrast, the amplitude of the relaxation becomes negligible for the ceramic sintered by SPS with smaller grain size $\left(\phi_{\text {grain }} \sim 3.4 \mu \mathrm{m}\right)$. This is thus very consistent with the conductivity plot (Fig. 10) which shows that the density of carriers in this small grain size SPS ceramics is two orders of magnitude smaller than in the large grain CS and SPS ceramics. In addition, it can be mentioned that the difference of the dielectric behavior can be understood by the decrease in the number of grain boundaries density with the increase of the grain size. Dielectric spectroscopy thus confirms that small-grain SPS ceramics can be efficiently reoxidized, thus reducing the density of free carriers. A summary of the conductive pathways according to the grain size is depicted schematically in Fig. 12. 
a) Intergranular conductive pathway

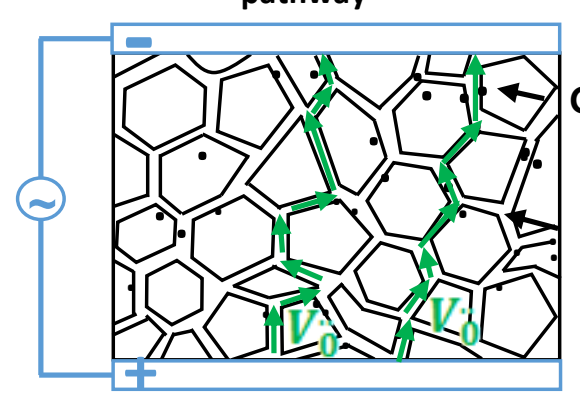

Electrode Pt b) inter/intragranular conductive pathway Grain Grain boundaries

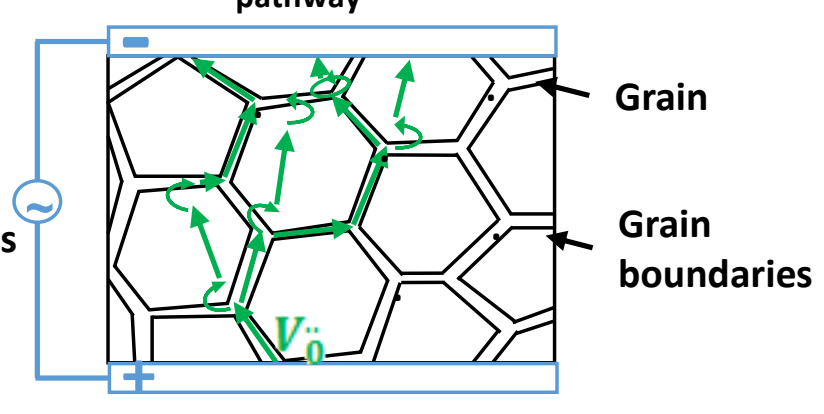

Electrode Pt

\begin{tabular}{ccc}
$0.5 \mu \mathrm{m} \leq \phi_{\text {grain }}<6 \mu \mathrm{m}$ & Grain size $\pi$ & $6 \mu \mathrm{m}<\phi_{\text {grain }} \leq 12 \mu \mathrm{m}$ \\
\hline pre-factor $\sigma^{\circ}: 1000-2000 \Omega^{-1} \cdot \mathrm{cm}^{-1}$ & Charge carriers $\lambda$ & $8000-10000 \Omega^{-1} . \mathrm{cm}^{-1}$
\end{tabular}

Fig. 12: Schematic drawn of the conduction mechanisms according to the ceramic grain size after SPS and subsequent re-oxidation at $600^{\circ} \mathrm{C}$.

\section{Conclusion}

To conclude, fast re-oxidation kinetics have been demonstrated in Spark Plasma Sintering sintered ceramics at $600^{\circ} \mathrm{C}$. This temperature is lower than that usually used in literature. Such ability is enhanced at grain size below $6 \mu \mathrm{m}$ due to a low stability of charged defects attributed to the low temperature and fast kinetics of the SPS densification. Impedance spectroscopy measurements performed on large grain-size ceramics obtained by SPS and conventional sintering show very similar transport properties assigned to both bulk and grain boundaries contributions. Decreasing the grain size in SPS ceramics does not modify the charge carriers mainly ascribed to oxygen vacancies but results in an easier re-oxidation step and consequently to a significant decrease of the density of free charge carriers. In these fine grain SPS ceramics, the transport mechanism is mainly governed by the grain boundaries, showing that the grain cores are fully oxidised. In addition the microstructural investigation has pointed out a remarkable increase of the grain size corresponding to the maximum of permittivity at room temperature in SPS ceramics compared to conventionally sintered samples. To summarize, the specific features of SPS and the re-oxidation step are beneficial for removing free charge carriers but can be detrimental to achieve the critical grain size for lattice-related properties like the dielectric permittivity. 


\section{References}

[1] G. Y. Yang, E. C. Dickey, C. A. Randall, D. E. Barber, P. Pinceloup, M. A. Henderson, R. A. Hill, J. J. Beeson, and D. J. Skamser, Oxygen nonstoichiometry and dielectric evolution of $\mathrm{BaTiO}_{3}$.Part I - Improvement of insulation resistance with reoxidation, J. Appl. Phys. 96 (2004) 7492-7499.

[2] M. Maglione, G. Philippot, D. Levasseur, S. Payan, C. Aymonier and C. Elissalde, Defect chemistry in ferroelectric perovskites: long standing issues and recent advances, Dalton Trans. 44 (2015) 13411-3418.

[3] Z. Zhao, V. Buscaglia, M. Viviani, M. Buscaglia, L. Mitoseriu, A. Testino, M. Nygren, M. Johnsson and P. Nanni., Grain-size effects on the ferroelectric behavior of dense nanocrystalline $\mathrm{BaTiO}_{3}$ ceramics, Phys. Rev. B. 70 (2004) 024107/1-024107/8.

[4] F. Maglia, I. G. Tredici and U. Anselmi-Tamburini, Densification and properties of bulk nanocrystalline functional ceramics with grain size below $50 \mathrm{~nm}$, J. Eur. Ceram. Soc. 33 (2013) 1045-1066.

[5] T. Hungria, M. Alguero, A. B. Hungria and A. Castro, Dense, fine-grained $\mathrm{Ba}_{1-\mathrm{x}} \mathrm{Sr}_{\mathrm{x}} \mathrm{TiO}_{3}$ ceramics prepared by the combination of mechanosynthesized nanopowders and Spark Plasma Sintering, Chem. Mater. 17 (2005) 6205-6212.

[6] Y. Gao, V. V. Shvartsman, D. Gautam, M. Winterer and D. C. Lupascu, Nanocrystalline barium strontium titanate ceramics synthesized via the "organosol" route and Spark Plasma Sintering, J. Am. Ceram. Soc. 97 (2014) 2139-2146.

[7] C. Elissalde, U.-C. Chung, G. Philippot, J. Lesseur, R. Berthelot, D. Sallagoity, M. Albino, R. Epherre, G. Chevallier, S. Buffière, A. Weibel, D. Bernard, J. Majimel, C. Aymonier, S. Mornet, C. Estournès and M. Maglione, J. Adv. Dielect. 5 (2015) 1530001/1$1530001 / 11$.

[8] G.Philippot, M. Albino, R. Epherre, G. Chevallier, Y. Beynet, C. Manière, A. Weibel, A. Peigney, M. Deluca, C. Elissalde, M. Maglione, C. Aymonier, and C. Estournès, Local Distortions in Nanostructured Ferroelectric Ceramics through Strain Tuning, Adv. Electron. Mater. 1 (2015) 1500190/1- 1500190/8.

[9] H. Han, C. Davis, and J. C. Nino, Variable Range Hopping Conduction in $\mathrm{BaTiO}_{3}$ Ceramics Exhibiting Colossal Permittivity J. Phys. Chem. 118 (2014) 9137-9142.

[10] H. Han, C. Voisin, S. Guillemet-Fritsch, P. Dufour, C. Tenailleau, C. Turner, J. C. Nino, Origin of colossal permittivity in $\mathrm{BaTiO}_{3}$ via broadband dielectric spectroscopy, J. Appl. Phys. 113 (2013) 1024102/1-1024102/8.

[11] L. Curecheriu, S.B. Balmus, M.T. Buscaglia, V. Buscaglia, A. Ianculescu, L. Mitoseriu, Grain Size-Dependent Properties of Dense Nanocrystalline Barium Titanate Ceramics, J. Am. Ceram. Soc. 95 (2012) 3912-3921. 
[12] H. Han, D. Ghosh, J. L. Jones, J. C. Nino, Colossal Permittivity in Microwave-Sintered Barium Titanate and Effect of Annealing on Dielectric Properties, J. Am. Ceram. Soc. 96 (2013) 485-490.

[13] S. Yoon, J. Dornseiffer, Y. Xiong, D. Grüner, S. Shen, S. Iwaya, C. Pithan, R. Waser, Spark plasma sintering of nanocrystalline BaTiO3-powders: Consolidation behavior and dielectric characteristics, J. Eur. Ceram. Soc. 31 (2011) 1723-1731.

[14] T. Al-Naboulsi, M. Boulos, C. Tenailleau, P. Dufour, M. Zakhour, S. Guillemet-Fritsch, Elaboration and characterization of barium titanate powders obtained by the mechanical activation of barium nitrate and titanate oxide, and electrical properties of the ceramics sintered by SPS, J. Ceram. Process. Res. 17 (2016) 870-875.

[15] R. Licheri, S. Fadda, R. Orrù, G. Cao, V. Buscaglia, Self-propagating high-temperature synthesis of barium titanate and subsequent densification by spark plasma sintering (SPS), J. Eur. Ceram. Soc. 27 (2007) 2245-2253.

[16] W. Luan, L. Gao, H. Kawaoka, T. Sekino, K. Niihara, Fabrication and characteristics of fine-grained BaTiO3 ceramics by spark plasma sintering, Ceram. Inter. 30 (2004) 405-410.

[17] V. Buscaglia, M. Viviani, M.T. Buscaglia, P. Nanni, L. Mitoseriu, A. Testino, E. Stytsenko, M. Daglish, Z. Zhao, M. Nygren, Nanostructured barium titanate ceramics, Pow. Techno. 148 (2004) 24-27.

[18] M. T. Buscaglia, V. Buscaglia, M. Viviani, J. Petzelt, M. Savinov, L. Mitoseriu, A. Testino, P. Nanni, C. Harnagea, Z. Zhao and M. Nygren, Ferroelectric properties of dense nanocrystalline $\mathrm{BaTiO}_{3}$ ceramics, Nanotech. 15 (2004) 1113-1117.

[19] B. Li, X. Wang, M. Cai, L. Hao, L. Li, Densification of uniformly small-grained $\mathrm{BaTiO}_{3}$ using spark-plasma-sintering, Mater. Chem. Phys. 82 (2003) 173-180.

[20] T. Takeuchi, Y. Suyama, D. C. Sinclair, H. Kageyama, Spark-plasma-sintering of fine $\mathrm{BaTiO}_{3}$ powder prepared by a sol-crystal method, J. Mater. Sci. 36 (2001) 2329-2334.

[21] T. Takeuchi, M. Tabuchi, H. Kageyama, Y. Suyama, Preparation of Dense $\mathrm{BaTiO}_{3}$ Ceramics with Submicrometer Grains by Spark Plasma Sintering, J. Am. Ceram. Soc. 82 (1999) 939-943.

[22] T. Takeuchi, E. Bétourné, M. Tabuchi, H. Kageyama, Y. Kobayashi, A. Coats, F. Morisson, D. C. Sinclair, A. R. West, Dielectric properties of spark-plasma-sintered $\mathrm{BaTiO}_{3}$, J. Mater. Sci, 34 (1999) 917-924.

[23] Y. Tan, J. Zhang, Y. Wu, C. Wang, V. Koval, B. Shi, H. Ye, R. McKinnon, G. Viola, H. Yan, Unfolding grain size effects in barium titanate ferroelectric ceramics, Sci. Rep. 5, 9953; DOI:10.1038/srep09953 (2015).

[24] F. Q. Guo, B. H. Zhang, Z. X. Fan, X. Peng, Q. Yang, Y. X. Dong, R. R. Chen, Grain size effects on piezoelectric properties of BaTiO3 ceramics prepared by spark plasma sintering, J. Mater. Sci: Mater. Electron. 27 (2016) 5967-5971. 
[25] R.E. Stanculescu, C.E.Ciomaga, N.Horchidan, C. Galassi, F. M. Tufescu, L.Mitoseriu, The influence of post-sintering re-oxidation treatment on dielectric response of dense and porous $\mathrm{Ba}_{0.70} \mathrm{Sr}_{0.30} \mathrm{TiO}_{3}$ ceramics, Ceramics International 42 (2016) 527-536.

[26] C. Voisin, S. Guillemet-Fritsch, P. Dufour, C. Tenailleau, H. Han and J.C. Nino, Influence of Oxygen Substoichiometry on the Dielectric Properties of $\mathrm{BaTiO}_{3-\delta}$ Nanoceramics Obtained by Spark Plasma Sintering, Inter. J. Appl. Ceram. Techno. 10 (2013) 122-133.

[27] H. Zhang, X. Deng, T. Li, W. Zhang, R. Chen, W. Tian, J. Li, X. Wang, L. Li, Extrinsic effects on dielectric response of ultrafine grain $\mathrm{BaTiO}_{3}$ ceramics, Appl. Phys. Lett. 97 (2010) 162913/1-162913/3.

[28] R. A. De Souza, C.Voisin, H. Schraknepper, M. Teusner, M. Kessel, P. Dufour, C. Tenailleau, S. Guillemet-Fritsch, Complex diffusion behavior of oxygen in nanocrystalline $\mathrm{BaTiO}_{3}$ ceramics, Phys. Chem. Chem. Phys. 16 (2014) 2568-2575.

[29] H. Hamorin, R. Jiménez, M. Deluca, J. Ricote, T. Hungria, A. Castro and M. Alguero, Nanostructuring Effects in Piezoelectric $\mathrm{BiScO}_{3}-\mathrm{PbTiO}_{3}$ Ceramics, J. Am. Ceram. Soc. 97 (2014) 2802-2809.

[30] J. Liu, Z. Shen, M. Nygren, T. W. Button, Spark Plasma Sintering Behaviour of NanoSized $(\mathrm{Ba}, \mathrm{Sr}) \mathrm{TiO}_{3}$ Powders: Determination of Sintering Parameters Yielding Nanostructured Ceramics, J. Am. Ceram. Soc. 89 (2006) 2689-2694.

[31] G. Arlt, D. Hennings and G. de With, Dielectric properties of fine grained barium titanate ceramics, J. Appl. Phys. 58 (1985) 1619-1625.

[32] O. Bidault, P.Goux, M. Kchikech, M. Belkaoumi and M. Maglione, Space-charge relaxation in perovskites, Phys.Rev. B 49 (1994) 7868-7873. 